\title{
DESMISTIFICANDO A PROTEÇÃO POR PATENTES NAS UNIVERSIDADES
}

\author{
Marcelo Gomes Speziali* \\ Instituto de Química, Universidade Federal do Rio Grande do Sul, Av. Bento Gonçalves, 9500, 91501-570 Porto Alegre - RS, Brasil \\ Pedro Pires Goulart Guimarães \\ Departamento de Fisiologia e Biofísica, Instituto de Ciências Biológicas, Universidade Federal de Minas Gerais, Av. Pres. Antônio \\ Carlos, 6627, 31270-901 Belo Horizonte - MG, Brasil
}

Rubén Dario Sinisterra

Departamento de Química, Instituto de Ciências Exatas, Universidade Federal de Minas Gerais, Av. Pres. Antônio Carlos, 6627, 31270-901 Belo Horizonte - MG, Brasil

Recebido em 19/11/11; aceito em 4/3/12; publicado na web em 15/6/12

\begin{abstract}
DESMYSTIFYING PATENT PROTECTION IN UNIVERSITIES. Brazilian universities and research institutions still fail to protect the knowledge and technology produced by their community of students, staff and professors while Intellectual Property (IP) issues along with the role of patents and their strategic management in educational and research institutions remain taboo or misunderstood. The focus of this work was to demystify these subjects, including IP, patents and their requirements, the decision to patent as well as tips for successful patenting. Any student, professor or researcher of an educational or research institution can invent and protect their technology. This paper shows how to make such a patent application.
\end{abstract}

Keywords: patent; patent strategy; industrial property.

\section{INTRODUÇÃO}

A produção científica no Brasil caracteriza-se por ser muito recente, datando dos últimos 100 anos, e tem uma grande concentração institucional nas universidades públicas e centros de pesquisa e, com honrosas exceções, em instituições privadas, como consequência das políticas públicas em ciência e educação no país. ${ }^{1}$ Esse é, certamente, ainda um dos grandes desafios no sistema nacional de inovação brasileiro - transferência da tecnologia gerada nas universidades e centros de pesquisa para a indústria, de tal forma que sejam gerados novos processos e produtos, intensivos em conhecimento, oriundos dessas instituições. O uso e a prática do sistema de propriedade industrial (PI) pelas universidades e pelos centros de pesquisa, com destaque para a tecnologia protegida por patentes, cria um ambiente favorável ao desenvolvimento científico-tecnológico e econômico do país. O uso conjunto das informações divulgadas nos documentos de patente e dados econômicos pode, além de tudo, auxiliar o planejamento estratégico de instituições, de políticas públicas e diretrizes industriais. ${ }^{2} \mathrm{Tal}$ sistema viabiliza o movimento sinergístico entre a produção intelectual pela academia e o processo de licenciamento e transferência de tecnologia para o setor empresarial.

Entre 2001 e 2008, as maiores universidades brasileiras protocolaram 1.359 depósitos de patentes junto ao Instituto Nacional de Propriedade Industrial (INPI), superando os 933 pedidos das 10 empresas que mais inovam no Brasil. ${ }^{3}$ Quando são analisados os dados coletados pelos núcleos de inovação tecnológica em 2010, verifica-se que as Instituições de Ciência e Tecnologia, ICT's, brasileiras (universidades e centros de pesquisa públicos e privados) passaram de 941 pedidos de patentes em 2006 para 2313 em 2009. ${ }^{4}$ Esses dados reforçam ainda a importância da difusão e do uso dos mecanismos de proteção, tanto pela academia quanto pelas empresas brasileiras, visando o aproveitamento de novas oportunidades de negócio a partir de tecnologias baseadas em conhecimento.

\footnotetext{
*e-mail: marcelospz@yahoo.com.br
}

Os direitos exclusivos estabelecidos pelo sistema de patentes permitem ao titular impedir que terceiros usem comercialmente, sem sua autorização, a tecnologia protegida. Além disso, os documentos de patentes exigem a revelação do processo ou produto, com suficiência descritiva, por seu proprietário. Mesmo estando protegido, o objeto preterido na patente pode, ainda assim, ser explorado sem fins comerciais, principalmente como fonte de inspiração para novos desenvolvimentos na empresa ou para inspiração na resolução de problemas no estado da arte e da técnica pela pesquisa científica das ICT’s. Pode servir ainda como fonte de estudo para a geração de políticas públicas para a consolidação do sistema nacional de inovação e política industrial, bem como o monitoramento tecnológico de empresas e/ou do país, entre outras. Depois de expirado o período de exclusividade então concedido, a invenção pode ser livremente utilizada por terceiros. Essa "troca" entre proteção e divulgação corrobora a vertente de que a patente não impede o desenvolvimento científico tecnológico.

Estudos reforçam que $80 \%$ de todo o conhecimento técnico só é publicado através da documentação de patentes, o que demonstra um papel central das patentes no desenvolvimento tecnológico, científico e econômico do país. ${ }^{5}$

Em face da relevância do assunto, o presente artigo teve como objetivo descrever os passos para a obtenção de um depósito de patente na área específica da Química. Pretende-se, com isso, elucidar alguns pontos chave do processo de patenteamento dentro das universidades e centros de pesquisa, de modo a torná-lo mais transparente e acessível aos pesquisadores, professores e alunos.

\section{DA IDEIA À PROTEÇÃo}

Analisando a definição que aparece nos dicionários - a Química é a ciência da matéria, estuda a estrutura, composição, propriedades e reações e transformações dos materiais - verifica-se que é uma ciência central, uma vez que estuda a quebra e formação de novas ligações através de novos ou velhos processos, gerando novas moléculas ou produtos. 
Dessa forma, a Química é uma das áreas onde os conceitos de propriedade industrial e proteção podem ser usados de forma mais intensiva. Podem ser obtidas moléculas com atividades biológica e farmacológica, propriedades físico-químicas melhores que as já conhecidas, materiais inteligentes, moléculas que mimetizam os sistemas biológicos, novos materiais condutores, novos cristais líquidos, formulações de produtos naturais, novos processos de obtenção de produtos naturais, biomateriais, entre muitas outras. Para a obtenção de moléculas já conhecidas e de grande apelo comercial, vários novos processos de síntese são desenvolvidos todos os dias. Esse processo dinâmico criativo para a obtenção de uma nova molécula começa com uma análise detalhada da estrutura de moléculas pré-existentes. Em algumas situações, são usadas as ferramentas de relação estrutura-atividade (SAR), bem como a relação quantitativa química-atividade biológica (QSAR), ou entre a estrutura química e algum tipo de propriedade físico-química (QSPR) as quais permitem planejar, sintetizar e testar novas moléculas ${ }^{6}$ que, às vezes, podem ser mais eficientes do que as já conhecidas no estado da arte e, como consequência, mais atrativas para futuros negócios.

Assim, ao inventar uma nova molécula, um novo processo, ou uma nova formulação (em alguns casos, um novo uso para o composto já conhecido) é possível divulgar o trabalho através de uma publicação científica com o intuito de divulgação, bem como protegê-lo através de um documento de patente, visando à disponibilização de novos produtos para a sociedade.

Segundo a Lei 9279/96, conhecida como Lei de Propriedade Industrial (LPI) de 14/5/1996, uma patente é: "Um título de propriedade temporária sobre uma invenção outorgado pelo Estado aos inventores ou outras pessoas físicas ou jurídicas detentoras de direitos sobre a criação". ${ }^{7}$ Em contrapartida, o inventor se obriga a revelar detalhadamente todo o conteúdo técnico da matéria protegida pela patente.

"Durante o prazo de vigência da patente (20 anos no caso de patente de invenção, PI e 15 anos no caso de modelo de utilidade, MU), o titular tem o direito de excluir terceiros, sem sua prévia autorização, de atos relativos à matéria protegida, tais como fabricação, comercialização, importação, uso, venda, etc.”.?

Um documento de patente é um documento com três bases fundamentais, a saber: legal, técnico e comercial. Assim, a análise técnico-legal é feita por especialistas nas áreas tecnológicas, bem como por profissionais que usem o arcabouço legal, nacional e internacional, na área de patentes, como a Lei $9279,{ }^{8}$ o Ato Normativo $127 / 97,{ }^{9}$ do Instituto Nacional da Propriedade Industrial e o Patent Cooperation Treaty - $P C T,{ }^{10}$ como marco legal internacional ou regulamentação dos outros países onde se pretende depositar a patente.

No Brasil, recentemente, foi promulgada a Lei de Inovação Tecnológica No 10.973, de 2004, e regulamentada em 11/10/2005 pelo Decreto $\mathrm{N}^{\mathrm{0}}$ 5.563. ${ }^{11}$ Essa lei regula, entre outros assuntos, os estímulos para a participação de Instituições Científicas e Tecnológicas (ICT's) no processo de inovação; para a inovação nas empresas; para o inventor independente; para a criação de fundos de investimentos para a inovação. É a primeira lei brasileira que trata do relacionamento entre universidades (e instituições de pesquisa) e empresas e da criação dos Núcleos de Inovação Tecnológica, NIT's, com o intuito de fazer gestão estratégica da propriedade intelectual das ICT's brasileiras.

Esse processo de regulação da PI dos NIT's trouxe como consequência o amadurecimento institucional dos mesmos; nesse contexto, foi criado o Fórum Nacional de Gestores de Inovação e Transferência de Tecnologia - FORTEC, em 2006, que reuniu 43 NIT's em 2006 e passou para 191 associados em 2011, em todas as regiões do país.

Nesse sentido, a responsabilidade dos NIT's, dentro ou fora das universidades, é justamente fornecer informações para os novos inventores sobre os procedimentos legais e a abrangência tecnológica para o depósito e processo de prossecução de uma patente. A leitura e a análise desses documentos, às vezes, é densa e demanda tempo, o que acaba desestimulando novos inventores. Vale a pena salientar que os documentos de patentes são fontes inesgotáveis de informação, conhecimento, tecnologia e, sobretudo, fonte de estratégia para resolução de problemas.

Para uma "possível" invenção ser patenteada ela deve apresentar os seguintes requisitos: novidade, atividade inventiva e aplicação industrial.

Não são patenteáveis as descobertas, teorias científicas e métodos matemáticos; concepções puramente abstratas; esquemas, planos, princípios ou métodos comerciais, contábeis, financeiros, educativos, publicitários, de sorteio e de fiscalização; as obras literárias, arquitetônicas, artísticas e científicas ou qualquer criação estética; programas de computador em si; apresentação de informações; regras de jogo; técnicas e métodos operatórios ou cirúrgicos, bem como métodos terapêuticos ou de diagnóstico, para aplicação no corpo humano ou animal; e o todo ou parte de seres vivos naturais e materiais biológicos encontrados na natureza, ou ainda que dela isolados, inclusive o genoma ou germoplasma de qualquer ser vivo natural e os processos biológicos naturais. ${ }^{8}$ Ainda considerando as características que tornam uma "possível" invenção não patenteável, tem-se que: não é patenteável o que for contrário à moral, aos bons costumes e à segurança, à ordem e à saúde públicas; as substâncias, matérias, misturas, elementos ou produtos de qualquer espécie, bem como a modificação de suas propriedades físico-químicas e os respectivos processos de obtenção ou modificação, quando resultantes de transformação do núcleo atômico; e o todo ou parte dos seres vivos, exceto os micro-organismos transgênicos que atendam aos três requisitos de patenteabilidade - novidade, atividade inventiva e aplicação industrial e que não sejam mera descoberta. Pela definição da lei de propriedade industrial, micro-organismos transgênicos são organismos, exceto o todo ou parte de plantas ou de animais, que expressem, mediante intervenção humana direta em sua composição genética, uma característica normalmente não alcançável pela espécie em condições naturais. ${ }^{8}$

Uma nova molécula com um efeito surpreendente associado (ex. ação herbicida, fungicida, cristal líquido, alta condutividade, fármaco que traga um efeito sinérgico, etc.) e que não seja conhecida no estado da técnica ou arte é factível de proteção por patente. Esses dois elementos são requisitos de patenteabilidade conhecidos como novidade e atividade inventiva, respectivamente. Vale a pena salientar que a atividade inventiva tem uma correlação direta com o acúmulo de pesquisa na área especifica, para chegar a identificar o efeito surpreendente.

Uma molécula pode constituir um pedido de patente de produto. Ainda devem ser investigados se o processo de obtenção da molécula é novo e, se há algumas possíveis composições ou formulações para a molécula em questão. Assim sendo, podem-se ter patentes para produtos, processos, composições e, em alguns países, há patentes também para usos e novos usos de moléculas conhecidas. Salienta-se que toda avaliação será feita sob a ótica dos três pilares fundamentais: tecnológico, legal e comercial.

O primeiro passo a ser executado para fazer um pedido de patente é realizar uma extensa busca na literatura técnica para verificar a novidade real da "possível" invenção, chamado de busca prévia no jargão da área. Vale a pena mencionar que em alguns países, como Estados Unidos e Brasil, existe um dispositivo chamado "período de graça". Com essa possibilidade, o inventor tem o prazo de até 1 ano, após a data de divulgação de sua invenção, para depositar o pedido de patente. No caso da Europa, exige-se a novidade absoluta, ou seja, qualquer publicação anterior à tecnologia que se deseja patentear é considerada anterioridade. Toda e qualquer informação divulgada e/ 
ou publicada anteriormente à data do depósito do pedido de patente é considerada como anterioridade e pode ser fundamental na decisão sobre a novidade ou a falta desta, na suposta invenção. Antes de escrever um pedido de patente, os bancos de dados científicos e tecnológicos devem ser intensivamente consultados. Livros da área, periódicos, notícias, internet, banco de dados de artigos científicos e de patentes, etc. devem também ser minuciosamente pesquisados. As patentes depositadas podem ser consultadas nos seguintes endereços de acesso gratuito:

- banco de dados do escritório de patentes americano - http://www. uspto.gov/; os documentos em PDF das patentes americanas podem ser encontrados em www.google.com/patents;

- banco de dados do escritório de patentes europeu - http:// ep.espacenet.com/ - e base de dados latinoamericana do escritório de patentes europeu - http://lp.espacenet.com/;

- banco de dados do escritório de patentes brasileiro - http://www. inpi.gov.br/;

- banco de dados de depósitos via Patent Cooperation Treaty (PCT) - http://www.wipo.int/pctdb/en/;

banco de dados de patentes chinesas - http://english.sipo.gov.cn/; outros bancos de dados gratuitos extremamente úteis, como www. patentlens.net, http://www.freepatentsonline.com/search.html e http://www.patentstorm.us/ podem e devem ser consultados. Apesar de limitados, possuem importantes informações a respeito da Propriedade Intelectual, patentes, transferência de tecnologia, TT e inovação, cursos on-line, bem como materiais informativos e curiosidades.

- Outra ferramenta considerada excelente, principalmente no que tange à busca de patentes, porém, disponível apenas para algumas instituições de ensino e pesquisa através do portal de periódicos CAPES é o Derwent Innovation Index (www.isiknowledge.com/). Vale lembrar que os softwares de busca Scifinder ${ }^{\circledR}$ e Reaxys ${ }^{\circledR}$ também são poderosas ferramentas, principalmente para busca de artigos e patentes na área de Química e estão disponíveis em algumas bibliotecas das universidades públicas brasileiras, sob-requisição.

Finalizada a busca prévia, e na hipótese que seja encontrado algum pedido de patente ou patente que antecipe o objeto da invenção, os inventores poderão desenvolver uma estratégia para superar a matéria encontrada e assim alcançar a proteção pretendida, destacando claramente a diferença do objeto da invenção em comparação aos documentos encontrados no estado da técnica. É comum encontrar o termo técnico para isto, design around.

Em suma, alguns pontos-chave para o sucesso no patenteamento de uma invenção são:

- avaliação da possibilidade do invento se tornar um produto ou processo que possa ser comercializado, através da busca prévia nas bases de dados;

- definição prévia dos direitos de cada participante na patente em caso de ganhos futuros auferidos - regulamentados hoje pela Lei de Inovação 10973/2004 e em alguns casos específicos de ICT's brasileiras é aplicada a fórmula de 33,3\% para a universidade, $33,3 \%$ para a unidade/departamento e $33,3 \%$ para o(s) inventor(es) - e manutenção do sigilo até o depósito de patente;

- seguir a regra de ouro - patentear primeiro, publicar e/ou produzir depois (essa regra pode ser aplicada também nos casos de exames de qualificação de pós-graduação e para o lançamento de produtos na indústria);

- avaliação da possibilidade do estabelecimento de convênios de pesquisa com empresas ou contratos que viabilizem a entrada do produto/processo no mercado.

A patente é um instrumento técnico-legal que assegura ao titular, muitas vezes, o início da introdução de um novo processo e/ou produto no mercado que, no caso da universidade, se dá através do processo de transferência de tecnologia para o setor produtivo específico.

Há possibilidades de se estabelecer parcerias universidade-empresa através de convênio de pesquisa para que os processos e/ ou produtos possam ser desenvolvidos em parceria e produzidos e comercializados pela empresa.

$\mathrm{O}$ instrumento de convênio permite estabelecer critérios para inovações nos processos e/ou produtos que podem ter parcerias de titularidade entre universidade e empresa.

Finalmente, chama-se atenção para custos com os depósitos de patentes nacionais que possuem uma taxa, segundo a tabela do INPI, ${ }^{12}$ de $\mathrm{R} \$ 235,00$ para inventores independentes e de $\mathrm{R} \$$ 95,00 no caso de pessoas naturais; microempreendedor individual; microempresas, empresas de pequeno porte e cooperativas assim definidas em lei; instituições de ensino e pesquisa; entidades sem fins lucrativos, bem como por órgãos públicos, quando se referirem a atos próprios. Para fazer um depósito internacional através do mecanismo PCT - Patent Cooperation Treaty, que hoje também pode ser feito no próprio INPI, paga-se uma taxa básica de $\mathrm{R} \$ 200,00$ para a transmissão do pedido para o escritório responsável em Genebra mais uma taxa de 1.330,00 CHF para o depósito.

Esse depósito PCT deve ser feito em até 12 meses após o primeiro depósito no Brasil, se for o caso, e garante a prioridade unionista. Esse mecanismo permite que a decisão de depósito internacional de patente possa ser adiada por mais 18 meses após depósito PCT, ou 30 meses contados do primeiro depósito no Brasil. Nesse momento toma-se, também, outra decisão importante - a escolha dos países onde se pretende depositar a patente internacionalmente depois de vencidos os prazos indicados acima. Ainda quanto ao depósito internacional, é necessário nomear uma autoridade de busca (o Brasil é uma opção recente, 2010), com o custo de $\mathrm{R} \$ 2.250,00$ ou $\mathrm{R} \$ 900,00$ para pessoa física, ${ }^{12}$ com o intuito de se fazer uma análise prévia de patenteabilidade e o chamado exame preliminar. Ressalta-se que esses custos são básicos e sempre serão acrescidos de honorários de advogados e procuradores nos países em que o depósito será feito.

Um depósito de patente deve ser bem pensando para evitar custos desnecessários, por isso é de extrema importância fazer uma avaliação das forças e fraquezas da patente com relação aos quesitos tecnológicos, legais e de mercado. Tal avaliação pode fornecer elementos para se considerar a manutenção, ou o abandono de uma patente, em um dado momento. É certo que os custos de manutenção de patentes nacionais e internacionais são elevados e os mesmos são relativizados e/ou recuperados quando as patentes são transferidas para o setor industrial para produção e comercialização.

\section{ESTRUTURA DO DOCUMENTO DE PATENTES - RELATÓRIO DESCRITIVO}

Os sites dos escritórios de patentes apresentam uma grande quantidade de informações sobre relatórios, interpretações das leis dos seus respectivos países e, mesmo, algumas técnicas e dicas de escrita de relatórios. O site da WIPO - OMPI (Organização Mundial da Propriedade Intelectual), além de tudo, ainda disponibiliza alguns cursos à distância ministrados pela própria academia da OMPI. Vários livros e manuais sobre patentes, com linguagem direcionada ao público da área de Química e ciências correlatas podem ser encontrado na literatura. ${ }^{13}$

A Figura 1 exemplifica, de modo simplificado, o processo de desenvolvimento de uma tecnologia, suas etapas e possibilidades. As pesquisas em fase de bancada de um laboratório geram resultados que podem ser divulgados em forma de artigos científicos, congressos, livros, etc. ou podem ser protegidos. A proteção de resultados científicos se dá através do know how ou da patente. A divulgação 
de um resultado resultará citações para os autores; já a patente, além das tradicionais citações, implica na possibilidade de ser licenciada. O licenciamento pode ser feito para empresas que tenham interesse em fazer o scale up da tecnologia e, consequentemente, dar seguimento ao processo de inovação ou para os próprios inventores, que desejem começar um novo empreendimento, todas essas situações são regulamentadas pela Lei de Inovação 10.973/2004.

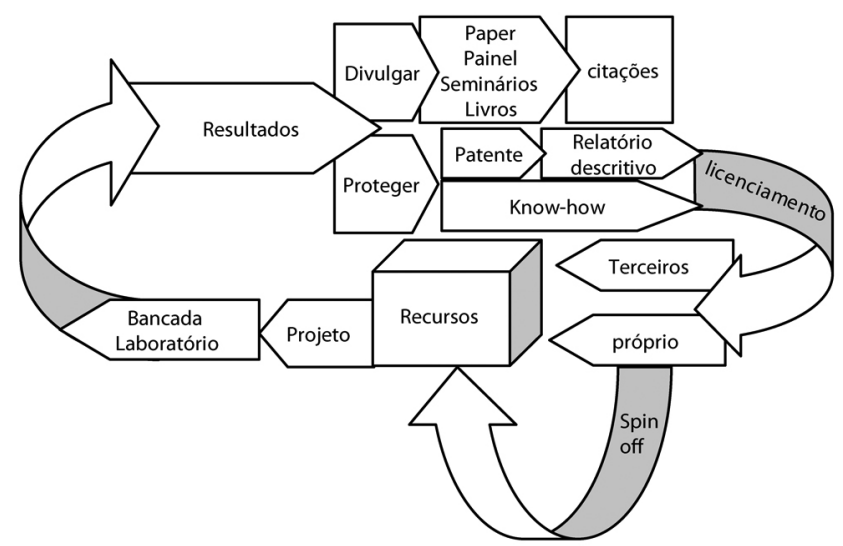

Figura 1. Fluxograma do processo de desenvolvimento de uma tecnologia

Nos casos em que a tecnologia surge a partir de um grupo de pesquisa da universidade e é implantada por uma empresa nascente, também na própria universidade, dá-se o nome de spin off acadêmico. Vários casos de sucesso de empresas do tipo spin off podem ser encontrados no site do NIT de Oxford - ISIS Innovation, ${ }^{14}$ do Massachusetts Institute of Technology- MIT ${ }^{15}$ e da Universidade de Stanford ${ }^{16}$ como exemplos da dinâmica dos mecanismos de transferência de tecnologia. Tanto no licenciamento próprio quanto para terceiros serão gerados royalties que retornarão para a universidade, para o laboratório em que a tecnologia foi desenvolvida e para os inventores da patente.

Um documento de patente (Figura 2) é composto basicamente de título, campo da invenção, estado da técnica - apresentação dos problemas existentes no estado da técnica, apresentação resumida da invenção, descrição detalhada da invenção, exemplos (contendo materiais, métodos, resultados e discussão), reivindicações, figuras - quando for o caso, e resumo. O trabalho de construção de um bom relatório descritivo deve ser a quatro ou mais mãos, pois o inventor sempre terá o melhor ou mais preciso entendimento do processo e/ ou produto em questão.

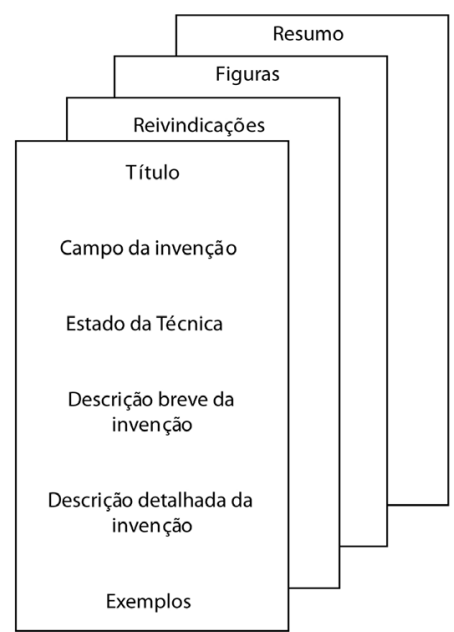

Figura 2. Estrutura de um relatório descritivo
O relatório descritivo deve ser redigido pensando em paralelo e, sempre que possível, comparando os problemas encontrados no estado da técnica com as soluções propostas pela invenção, ressaltando os pontos relevantes da invenção. Por outro lado, as reivindicações da patente devem sempre ser redigidas mantendo um equilíbrio entre soluções e estratégias propostas pela invenção com o mercado vislumbrado pela tecnologia.

Ao se escrever um relatório descritivo é bom conhecer todos os tópicos necessários e saber como interligá-los. Mais especificamente: - o título deve ser conciso e retratar bem o escopo da proteção produto, processo, composição, uso, etc.;

- o campo da invenção deve descrever de forma clara a área da invenção, bem como as principais características do invento quando comparado às tecnologias encontradas no estado da técnica. Em outras palavras, o campo da invenção pode ser tratado como um resumo direto e objetivo da tecnologia em questão;

- o estado da técnica é uma breve descrição das tecnologias correlatas com a invenção em questão. O conhecimento do estado da técnica constitui, com base na busca prévia, nos bancos de dados de patentes, artigos científicos e, quando for o caso, bancos de informações de divulgação não científicas e/ou tecnologias de empresas na área em questão;

- a apresentação resumida da invenção, assim como o campo da invenção, deve se apresentar como um resumo direto e objetivo da tecnologia proposta, contendo os fatores inventivos e inovadores que conferem novidade à tecnologia em questão;

- a descrição detalhada da invenção é a parte do relatório em que a invenção proposta é descrita de modo bem detalhado, contendo todas as etapas do processo, detalhes do produto ou da composição, bem como os diversos modos de se reproduzir a invenção proposta;

- os exemplos devem ser descritos com a mesma linguagem utilizada nos cadernos de laboratório, contendo, na íntegra, o modo como a invenção foi testada e experimentada, de modo claro e objetivo, sendo possível que um técnico no assunto, com conhecimento mediano, possa reproduzir os experimentos descritos; as reivindicações são consideradas o coração da patente. Além do valor científico-tecnológico, as reivindicações possuem um valor jurídico-legal extremamente relevante. Os direitos de inventor são considerados essencialmente pelo teor das reivindicações. Salienta-se que todo tipo de informação revelada nas reivindicações deve estar relatada e fundamentada no relatório descritivo, garantindo assim a suficiência descritiva;

- $\quad$ as figuras, quando for o caso, podem ser incluídas em um anexo ao relatório descritivo, de modo a deixar mais compreensíveis as características da invenção. Podem ser anexadas figuras, desenhos, gráficos e análises que ajudem a compreender melhor a invenção proposta;

- o resumo, apresentado no final, pode ser constituído pelo mesmo texto utilizado no campo da invenção, destacando as características mais relevantes da invenção.

\section{ORIENTAÇÕES SOBRE A ESCRITA DE UM RELATÓRIO DESCRITIVO}

Antes de escrever um relatório descritivo, propriamente dito, devem-se assumir algumas indagações e ponderar alguns pontos fundamentais que podem ser de vital importância para a construção de um documento forte de patente:

- faça uma breve descrição da invenção. Saliente as aplicações bem como vantagens tecnológicas;

- apresente, em forma de texto, um resumo das tecnologias relevantes que contenham alguma similaridade com a presente invenção; 
- construa, quando possível, um quadro ou tabela comparativa entre as características mais relevantes da invenção e as tecnologias encontradas no estado da técnica. Isso ajudará a relatar de forma mais clara e concisa as vantagens da invenção;

- verifique em quais pontos as patentes do estado da técnica falham;

- descreva como a sua invenção pode contribuir para solucionar estes problemas;

- caso pretenda proteger algum produto, indique as características que o diferem dos tradicionais e o podem tornar superior em qualidade;

- $\quad$ se pretender proteger processo, enfatize quais as vantagens que o seu processo apresenta frente aos tradicionais;

- ressalte como este novo processo proposto pode alterar as características finais do produto;

- verifique qual é o efeito surpreendente da presente invenção

- apresente de maneira ilustrativa alguns exemplos, sejam da aplicação do produto ou da rota de obtenção;

- redija sem usar no texto adjetivos como novo, inédito, fantástico, inovador, incrível ou outros quaisquer do gênero. Para que algo possa ser patenteável fica implícito que é novo e inédito, portanto, o uso destas características se torna desnecessário e redundante;

- verifique que aspectos econômicos e ambientais são de extrema importância para a divulgação da tecnologia e para atrair possíveis licenciadores, mas deve ficar claro que esses aspectos não acrescentam nada aos requisitos de patenteabilidade.

Algumas referências interessantes sobre patentes, estudos de casos na área de biotecnologia e opiniões críticas sobre a lei de patentes podem ser encontradas também na literatura científica. ${ }^{17}$

Com todas essas informações, é interessante que os novos inventores se organizem com um organograma de tarefas (Figura 3 ) e que cada etapa seja rigorosamente avaliada e executada.

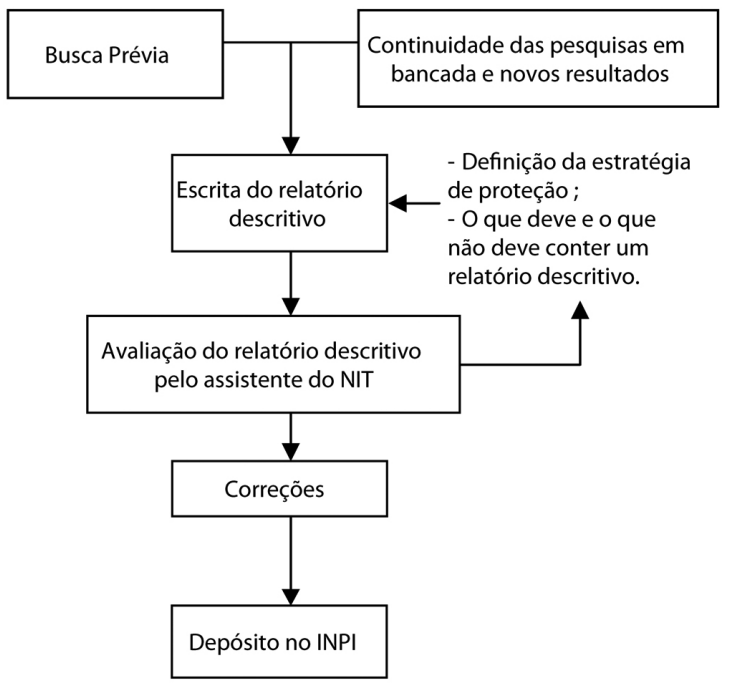

Figura 3. Fluxograma da elaboração de um pedido de patente

\section{Considerações sobre a busca prévia}

A busca no estado da arte, não é somente um passo obrigatório durante o processo de desenvolvimento e proteção de uma tecnologia, mas também pode se apresentar como uma ferramenta indispensável durante a construção do relatório descritivo. Apenas para ilustrar, abaixo são citadas algumas das muitas possibilidades de aproveitamento das informações recuperadas durante uma busca prévia:

- subsidiar e orientar o processo de tomadas de decisão em P\&D\&I;

- buscar tecnologias alternativas para a solução de problemas técnicos e de fontes de expertise;

- estudar o panorama tecnológico em um dado período de tempo;

- auxiliar decisões relativas à gestão de risco e inovações tecnológicas; melhorar a competitividade tecnológica de produtos e processos; garantir mercado; reduzir a incerteza de investimentos em P\&D\&I.

O processo de busca de informações na área da Química pode ser considerado um desafio, devido às diferentes representações de uma mesma molécula e à peculiaridade intrínsecas da área. ${ }^{18}$ Nomeclaturas triviais, nomes segundo IUPAC, nomes comerciais, InChI (International Chemical Identifier), SMILES (Simplified Molecular Input Line Entry Specification) ou fórmulas do tipo Markush $^{19}$ são apenas uns dos complicadores de uma busca especializada nessa área. Pode-se fazer uma busca por: estrutura química exata - quando se quer encontrar a estrutura exata na busca de patentes, com a limitação de que não serão encontrados os estereoisômeros, homólogos ou isômeros; subestrutura química - parte da estrutura ou grupo funcional de uma molécula maior, por exemplo, usando benzeno se acham benzenos substituídos, compostos aromáticos polissubstítuidos tais como naftaleno, antraceno, pireno, etc.; reações químicas específicas; etc..

Como o intuito de ilustrar a complexidade associada na busca de patentes em Química, apresenta-se a seguir um exemplo: uma molécula bastante conhecida na atualidade, o Viagra, possui diversas formas de ser representada, portanto, diversos modos de buscá-la na literatura, a saber: nome comercial - Viagra ou Citrato de Sildenafil ou Citrato de Sildenafila; nome segundo IUPAC - Citrato de 1-[4-etóxi-3-(6,7-di-hidro-1-metil-7-oxo-3-propil-1 $H$-pirazol[4,3-d] pirimidin-5-yl) fenilsulfonil] - 4-metilpiperazina; fórmula condensada $-\mathrm{C}_{22} \mathrm{H}_{30} \mathrm{~N}_{6} \mathrm{O}_{4} \mathrm{~S}$; número de registro no Chemical Abstracts - CAS 139755-83-2, dentre outros.

Um exemplo bem sucedido, e complexo, de representar uma molécula em uma patente pode ser encontrado nas reivindicações da EP 0463756B1 de propriedade da Pfizer Limited com o título: Pyrazolopyrimidinone antianginal agents. A estrutura da molécula do Viagra, nesta patente, está contida numa das muitas possibilidades de permutação dos grupos substituintes descritos nas reivindicações. Um típico exemplo de representação Markush de uma molécula:

- Reivindicação 1: um processo para preparar um composto de fórmula:

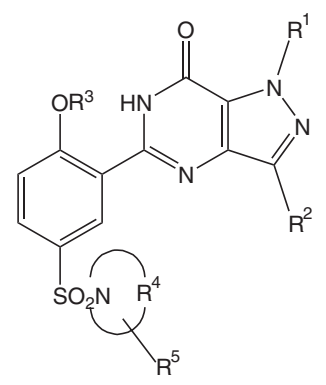

Fórmula 1

em que: $\mathrm{R}^{1}$ é $\mathrm{H}, \mathrm{C}_{1}-\mathrm{C}_{3}$ alquílico, $\mathrm{C}_{3}-\mathrm{C}_{5}$ cicloalquílico ou $\mathrm{C}_{1}-\mathrm{C}_{3}$ perfluoroalquílico; $\mathrm{R}^{2}$ é $\mathrm{H}, \mathrm{C}_{1}-\mathrm{C}_{6}$ alquílico opcionalmente substituído por $\mathrm{OH}$, $\mathrm{C}_{1}-\mathrm{C}_{3}$ alcóxi ou $\mathrm{C}_{3}-\mathrm{C}_{6}$ cicloalquílico ou $\mathrm{C}_{1}-\mathrm{C}_{3}$ perfluoroalquílico; $\mathrm{R}^{3}$ é $\mathrm{C}_{1}-\mathrm{C}_{6}$ alquílico, $\mathrm{C}_{3}-\mathrm{C}_{6}$ alquenil, $\mathrm{C}_{3}-\mathrm{C}_{6}$ alquinil $\mathrm{C}_{3}-\mathrm{C}_{7}$ cicloalquílico, $\mathrm{C}_{1}-\mathrm{C}_{6}$ perfluoroalquílico ou $\left(\mathrm{C}_{3}-\mathrm{C}_{6}\right.$ cicloalquílico $) \mathrm{C}_{1}-\mathrm{C}_{6}$ alquílico; $\mathrm{R}^{4}$ tomado junto com o átomo de nitrogênio ao qual está ligado completa um pirrolidinil, piperidínio, morfolínio ou $4-\mathrm{N}-\left(\mathrm{R}^{6}\right)$ piperazinil; $\mathrm{R}^{5}$ é $\mathrm{H}, \mathrm{C}_{1}-\mathrm{C}_{4}$ alquílico, $\mathrm{C}_{1}-\mathrm{C}_{3}$ alcóxi, $\mathrm{NR}^{7} \mathrm{R}^{8}$ ou $\mathrm{CONR}^{7} \mathrm{R}^{8} ; \mathrm{R}^{6}$ é $\mathrm{H}$, $\mathrm{C}_{1}-\mathrm{C}_{6}$ alquílico, $\left(\mathrm{C}_{1}-\mathrm{C}_{3}\right.$ alcóxi) $\mathrm{C}_{2}-\mathrm{C}_{6}$ alquílico, hidróxi $\mathrm{C}_{2}-\mathrm{C}_{6}$ alquílico, $\left(\mathrm{R}^{7} \mathrm{R}^{8} \mathrm{~N}\right) \mathrm{C}_{2} \mathrm{C}_{6}$ alquílico, $\left(\mathrm{R}^{7} \mathrm{R}^{8} \mathrm{NCO}\right) \mathrm{C}_{1}-\mathrm{C}_{6}$ alquílico, $\mathrm{CONR}^{7} \mathrm{R}^{8}$, $\mathrm{CSNR}^{7} \mathrm{R}^{8}$ ou $\mathrm{C}(\mathrm{NH}) \mathrm{NR}^{7} \mathrm{R}^{8}$; 
$\mathrm{R}^{7}$ e $\mathrm{R}^{8}$ são independentemente $\mathrm{H}, \mathrm{C}_{1}-\mathrm{C}_{4}$ aquílicos, $\left(\mathrm{C}_{1}-\mathrm{C}_{3}\right.$ alcóxi $)$ $\mathrm{C}_{2}-\mathrm{C}_{4}$ alquílicos ou hidroxílicos $\mathrm{C}_{2}-\mathrm{C}_{4}$ alquil; e sais farmaceuticamente aceitáveis que compreendem reagir um composto de fórmula:<smiles>[R]c1nn([Tl])c2c(=O)[nH]c(-c3cc(S(=O)(=O)O)ccc3O)nc12</smiles>

Fórmula 1A

na qual $\mathrm{R}^{1}, \mathrm{R}^{2}$ e $\mathrm{R}^{3}$ são previamente definidos e $\mathrm{Y}$ é cloro, bromo ou flúor, com um composto de fórmula:

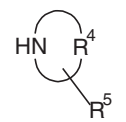

Fórmula 1B

na qual $\mathrm{R}^{4}$ e $\mathrm{R}^{5}$ são previamente definidos e opcionalmente convertidos ao produto requerido como um sal farmaceuticamente aceitável.

- Reivindicação 2: um processo como o da reivindicação 1 , no qual $\mathrm{R}^{1}, \mathrm{R}^{2}, \mathrm{R}^{4}$ e $\mathrm{R}^{5}$ são iguais à reivindicação 1 e $\mathrm{R}^{3}$ é $\mathrm{H}$ seguido de uma O-alquilação do fenol e opcionalmente convertido ao produto requerido como um sal farmaceuticamente aceitável.

Com todo esse panorama oferecido pelas ferramentas da Química, fica implícita a necessidade de um técnico especializado na área para escrever e analisar o conteúdo de patentes de Química.

\section{COMENTÁRIOS FINAIS}

A política de proteção industrial no Brasil ainda é jovem e precisa de maior difusão das suas possibilidades, implicações e limitações.

É necessária uma política sustentada de formação de pessoas com capacitação na área de Propriedade Industrial que ainda é escassa no país, tanto no nível técnico, legal e comercial, uma vez que se verifica aumento da demanda por proteção das tecnologias oriundas das universidades, centros de pesquisa e da indústria nacional. Na era da economia do conhecimento, uma patente é moeda de troca de valor apreciável. Uma patente pode levar à geração de um processo/produto no futuro, assim como fornecer conhecimento de ponta, inspiração e incentivo para futuras pesquisas e projetos, e induzir a formação de empresas de base tecnológica, estimulando o empreendedorismo dos novos alunos-inventores, bem como o aumento de emprego e renda para o país. Referências com o uso de tecnologias emergentes, desenvolvidas na academia, e que inspiram o empreendedorismo e a continuidade da inovação, podem ser encontradas no trabalho de Araújo e colaboradores. ${ }^{20}$ Todo esse potencial levará ao desenvolvimento sustentável do país visando à produção do conhecimento para gerar bem-estar e melhor qualidade de vida à sociedade. $\mathrm{O}$ meio adequado para o desenvolvimento, a proteção e a exploração de uma tecnologia emergente pode ser a razão de seu eminente sucesso ou fracasso. Para tanto, a escrita de um documento de patente bem fundamentado e pensando sempre em quem vai produzir e comercializar o novo processo e produto é o primeiro passo para o sucesso de uma tecnologia inovadora nascente.

\section{REFERÊNCIAS}

1. Chaimovich, H.; Estudos Avançados 2000, 14, 134; Zorzetto, R.; Razzouk, D.; Dubugras, M. T. B.; Gerolin, J.; Schor, N.; Guimarães, J. A.; Mari, J. J.; Braz. J. Med. Biol. Res. 2006, 39, 1513.

2. Nunes, J. d. S.; Oliveira, L. G. d.; Universidades Brasileiras - Utilização do Sistema de Patentes de 2000 a 2004, Instituto Nacional da Propriedade Industrial: Rio de Janeiro, 2007.

3. http://www.andifes.org.br/index.php?option=com_content\&task=view \&id=1811\&Itemid=104, acessada em Junho 2010 .

4. http://www.fortec-br.org/, acessada em Fevereiro 2012.

5. Mervyn, B.; World Patent Information 2005, 27, 309.

6. Kubinyi, H.; QSAR: Hansch Analysis and Related Approaches, WileyVCH Verlag GmbH: Weinheim, 2008; Barreiro, E. J.; Fraga, C. A. M.; Química medicinal As bases moleculares da ação dos fármacos, Artmed Ed. Ltda: Porto Alegre, 2001; Arroio, A.; Honório, K. M.; da Silva, A. B. F.; Quim. Nova 2010, 33, 694.

7. http://www.inpi.gov.br/index.php?option=com_content $\&$ view=article $\&$ $\mathrm{id}=60$ \&ltemid=96, acessada em Maio 2012.

8. Brasil; Lei No 9.279, de 14 de maio de 1996. Regula direitos e obrigações relativos à propriedade industrial.

9. Rio de Janeiro; Ato Normativo 127/97. Dispõe sobre a aplicação da Lei de Propriedade Industrial em relação às patentes e certificados de adição de invenção.

10. http://www.wipo.int/pct/en/texts/articles/atoc.htm, acessada em Fevereiro 2012.

11. Brasil; Lei $\mathrm{N}^{\mathrm{o}} 10.973$, de 2 de dezembro de 2004. Dispõe sobre incentivos à inovação e à pesquisa científica e tecnológica no ambiente produtivo e dá outras providências.

12. http://www.inpi.gov.br/images/stories/Tabela_Retribuicao_2012_Portal_ INPI.pdf, acessada em Fevereiro 2012.

13. Roberts, S.; Rudge, A.; A Complete Guide to Passing the European Qualifying Exam and Qualifying as a European Patent Attorney, $5^{\text {th }}$ ed., Sweet \& Maxwell: London, 2010; Miller, C. P.; Evans, M. J.; The Chemist's Companion Guide to Patent Law, John Wiley \& Sons Inc: New Jersey, 2010; Junghans, C.; Levy, A.; Intellectual Property Management A Guide for Scientists, Engineers, Financiers, and Managers, Wiley-VCH: Weinheim, 2006; OMPI; Manual de redação de patentes da Organização Mundial da Propriedade Intelectual; 2010.

14. http://www.isis-innovation.com/index.html, acessada em Novembro 2011.

15. http://materials.mit.edu/index.php?PID=262\&depth=2\&page_ type=simple_link_image_page, acessada em Fevereiro 2012.

16. http://ecorner.stanford.edu/index.html, acessada em Fevereiro 2012.

17. Rodrigues, A. de O.; Quim. Nova 1998, 21, 228; Soares, J. M.; Correa, M. C. D. V.; Quim. Nova 2010, 33, 1216; de Oliveira, L. G.; Suster, R.; Pinto, A. C.; Ribeiro, N. M.; da Silva, R. B.; Quim. Nova 2005, 28 suplemento, $\mathrm{S} 36$.

18. Gurulingappa, H.; Mueller, B.; Klinger, R.; Mevissen, H.-T.; HofmannApitius, M.; Friedrich, C. M.; Fluck, J.; Nineteenth Text REtrieval Conference, Gaithersburg, EUA, 2010.

19. Valance, E. H.; J. Chemical Documentation 1961, 1, 87.

20. Araújo, M. H.; Lago, R. M.; Oliveira, L. C. A.; Cabral, P. R. M.; Cheng, L. C.; Borges, C.; Filion, L. J.; Quim. Nova 2005, 28 suplemento, S26; Araújo, M. H.; Lago, R. M.; Oliveira, L. C. A.; Cabral, P. R. M.; Cheng, L. C.; Filion, L. J.; Quim. Nova 2005, 28 suplemento, S18. 